\title{
Educação e Pragmatismo: diálogos entre Aníbal Ponce, István Mészáros e Hannah Arendt
}

\begin{abstract}
Resumo: Educar para a liberdade e emancipação ou para formar profissionais aptos ao mercado de trabalho? Como a educação cedeu espaço ao pragmatismo e como refletir sobre alternativas a este modelo formativo? Pensar a educação é tarefa complexa e multidimensional, pois sua história não nasceu, tampouco se ampliou, de um movimento uniforme, homogêneo. A depender do lugar no mundo, os processos educacionais apresentaram-se de maneiras diferentes, cujo papel da educação variava a depender dos mandatários ou destinatários deste sistema. Alguns desses processos eram "bem-sucedidos" se considerarmos a minoria a ser alcançada. Quando, posteriormente, a educação atinge as classes trabalhadoras, seu foco é preparar mão de obra para o mercado de trabalho; busca-se exclusivamente um pragmatismo técnico. Nesse sentido, o presente artigo tem como objetivo refletir sobre processos e perspectivas educacionais, através de um diálogo entre os educadores Aníbal Ponce e István Mészáros e a filósofa Hannah Arendt. Dos autores nos utilizaremos para apontar como a história da educação inclinou-se, no decorrer dos séculos, ao pragmatismo; da autora, extrairemos uma perspectiva educacional que, acreditamos, surge como alternativa nos processos educacionais, cuja principal referência seja o próprio ser humano, ainda em formação. Não se trata, no entanto, de oferecer uma proposta pronta, que pretenda resolver o problema do pragmatismo de maneira completa ou simplista. Trata-se, na verdade, de refletir sobre possíveis caminhos que podem ser trilhados a partir do pensamento arendtiano.
\end{abstract}

Palavras-chave: Educação. Pragmatismo. Formação do Cidadão.

\section{Introdução}

Os mecanismos e processos educacionais sempre se deram de forma diversa e polissêmica. Ao longo da história, diferentes regiões e grupos guiaram sua educação de maneira completamente diferente uma das outras. Aníbal Ponce e István Mészáros, cada um à sua maneira, tratam desses modelos no decorrer das épocas e apontam, de forma crítica, como a educação se estabeleceu e quais grupos alcançou no desenrolar do processo histórico. Ao fazer isso, indicam como a educação quase sempre foi direcionada às classes abastadas, principalmente quando de sua institucionalização.

A educação, nesse sentido, em especial sob efeito do capitalismo nascente, inclinou-se para educar as classes dos organizadores em detrimento das classes dos executores. Conforme se verá no decorrer deste artigo, chegou-se ao ponto em que a desigualdade do sistema que se estabeleceu, o sistema capitalista, alcançou ín-
Ricardo Teixeira da Silva Universidade Federal do Amapá ricardokairos20@gmail.com Helena Cristina Guimarães Queiroz Simões Universidade Federal do Amapá simoeshcg@gmail.com 
dices desumanos cuja distância entre os que muito podem e tem e os que nada ou pouco possuem só se amplia; de fato, vive-se, hoje, dentro do modelo caracterizado pela desigualdade reinante.

A educação também se adequou ao sistema. Ao transformar-se em mercadoria excluiu as classes populares no sentido de uma formação crítica e libertária; a educação que as alcançam, ao ser pragmática, visa apenas sua formação enquanto classe operária, que trabalha e tem suas forças direcionadas para a manutenção dos privilégios de uma minoria. Dessa forma indagamos, baseados em Ponce e Meszáros, como a educação cedeu espaço ao pragmatismo e, com Arendt, como refletir sobre alternativas a este modelo formativo?

Aníbal Ponce dará o pano de fundo desses processos; István Mészáros falará sobre a necessidade de romper profundamente com a sistemática capitalista e não apenas reformá-la. Hannah Arendt, conforme adotado aqui, contribuirá com uma perspectiva educacional que vê na humanidade a própria saída da crise educacional que se estabeleceu desde a segunda metade do século XX. Apesar de essencialmente diferentes, uma vez que os dois primeiros autores são de orientação marxista - enquanto Arendt não o é -, utilizamos de perspectivas diversas no intuito de propor uma alternativa a partir, justamente, de um modo de pensar diferente, ao qual julgamos atual: o pensamento de Hannah Arendt.

Ao basear sua conceituação de liberdade na experiência grega da pólis, Hannah Arendt (2014) visa trazer a lume uma realidade que foi, no âmbito da política, solapada pelo estoicismo e cristianismo, que mudaram o campo da liberdade - antes vivida no contexto de homens que agiam em conjunto dentro da pólis - para o espaço de interiorização humana. Isso significa dizer que, a partir da ideia de liberdade interior, a liberdade migra do âmbito da política na esfera pública e passa a habitar o interior da alma humana.

Essa mudança da aplicação e existência da liberdade trouxe fortes implicações para uma vida interessada em conservar um mundo comum de homens plurais. De fato, a pregação cristã de abandono às coisas do mundo, segundo Arendt (2014), tirara completamente o foco dos indivíduos, em especial nos momentos de maior influência do Cristianismo, e ocasionaram o desinteresse pelos assuntos mundanos.

Conforme entende Almeida (2008), Hannah Arendt, ao desenvolver o processo de interiorização da liberdade confirma sua 
preocupação com a dignidade da ação política; isso se dá ao potencializar a liberdade como capacidade humana de fazer surgir algo novo, inesperado. Ainda de acordo com Almeida (2008), o que se tem é que Arendt vê na liberdade a própria capacidade de superar os processos históricos cristalizados criando uma ordem política e social capaz de construir algo novo, imprevisto e imprevisível. Essa liberdade, no entanto, se vê prejudicada pelo constante risco que sofre a educação frente ao pragmatismo.

Liberdade, nesse sentido, dependerá da singularidade de cada pessoa. Almeida (2008, p. 465), explica que a "educação [...] pode propiciar às crianças e aos jovens a possibilidade de desenvolver sua singularidade, contribuindo assim para que futuramente possam de fato realizar o dom da liberdade, renovando o mundo que herdaram". Além disso, é "nesse tempo entre o nascimento biológico, com o qual surge essa potência renovadora, e o momento no qual os novos poderão ativamente assumir sua liberdade e agirão, que se insere a educação". (ALMEIDA, 2008, p. 468)

Ao mesmo tempo que crítico e profundo, o pensamento de Hannah Arendt sobre Educação também propõe caminhos esperançosos que vê, na singularidade e pluralidade de cada ser humano, bem como em seu processo de renovação através de cada novo nascimento, a possibilidade de manutenção e reconstrução do mundo comum dos homens no plural. (ARENDT, 2013)

No que segue, elaboraremos algumas reflexões a partir de diálogos entre Aníbal Ponce, István Mészáros e Hannah Arendt. Trata-se de construir um caminho que vai do aparecimento do pragmatismo como objetivo central de determinados processos educacionais à superação desse mesmo modelo.

\section{Uma educação para poucos: o processo educacional e o problema do pragmatismo}

A humanidade experimentou, no decorrer do processo histórico, inúmeros estágios daquilo que hoje entendemos por educação. Sua forma institucionalizada surge em etapa muito posterior da história humana; o que ocorria, no início do tempo histórico registrável, eram processos naturais de educação que tinham como objetivo básico preparar os indivíduos naquilo que dizia respeito a sua subsistência. 
Ao acompanhar o processo de desenvolvimento educacional, no entanto, tem-se a noção clara de que, conforme amoldavam-se às classes sociais, estabelecendo relações cada vez mais complexas, a educação inclinava-se para a formação das classes dominantes que, em grande medida, usavam os conhecimentos adquiridos para manter seu domínio e sua hegemonia.

As sociedades primitivas eram tudo aquilo que a atual sociedade capitalista perdeu em termos de humanidade. Inicialmente, o que predominava era um tipo de comunismo tribal: o que era produzido era dividido entre os membros da tribo/clã/comunidade e eram consumidos imediatamente. O objetivo era claro: a subsistência. Este é um fator importante, pois se o objetivo era o alimento diário, noções como a de acumulação estavam ausentes nessas comunidades e, uma vez evitado o acúmulo material, é razoável pensar essas comunidades com baixa, ou nenhuma diferenciação dos indivíduos em termos econômicos. (PONCE, 2003)

Ponce (2003, p. 17) caracterizou as sociedades primitivas como "coletividade pequena, assentada sobre a propriedade comum da terra e unida por laços de sangue". Todas as pessoas eram livres e com iguais direitos, sendo regidos por um "conselho formado democraticamente por 'homens e mulheres'”. Vê-se, desde já, um contraste importante em relação a sociedade contemporânea, marcada fortemente pelos problemas sociais da desigualdade de gênero, como diferenças salariais, violência doméstica, e outras formas de machismo. (PONCE, 2003)

A educação das crianças, nesse contexto, se dava da seguinte maneira: até os sete anos de idade elas acompanhavam, junto aos cuidados dos adultos, o processo de coleta de alimentos; recebiam conforme seus esforços, além do cuidado conjunto da coletividade com todas as crianças existentes na comunidade. Elas, portanto, eram consideradas membros da comunidade, assim como os homens e as mulheres. (PONCE, 2003)

De maneira a clarificar o processo educacional das comunidades primitivas, Ponce (2003, p. 19) explica que "o ensino era para a vida e por meio da vida; para aprender a manejar o arco a criança caçava; para aprender a guiar um barco, navegava". Era uma educação pragmática, porém, sem ocupar o papel do pragmatismo da educação moderna que, de maneira geral, acaba por alienar e criar um campo fértil para a manipulação e o domínio. Na contemporaneidade, portanto, o pragmatismo age de maneira que, conforme 
defendemos, destrói aquilo de mais importante nos indivíduos: sua autonomia, sua qualidade como ser singular e plural.

Nesse contexto, Ponce (2003, p. 19) elabora uma questão pertinente: "Se não existia nenhum mecanismo educativo especial, nenhuma 'escola' que imprimisse às crianças uma mentalidade social uniforme, em virtude de que a anarquia da infância se transformava na disciplina da maturidade?". Este questionamento reflete um problema contemporâneo de grande magnitude: a relação entre Escola e Educação. Hannah Arendt também concordará com esse problema; para a autora, o processo de formação da criança para o mundo comum dos homens se dá de maneira abrangente, de maneira que leve em conta a criança como um sujeito, capaz de agir e de renovar o mundo. De fato, uma escola com conteúdos pré-determinados em sentido amplo mina a capacidade da criança de trazer algo novo ao mundo. (ARENDT, 2013) Nesse sentido, vale ressaltar que "a educação na comunidade primitiva era uma função espontânea da sociedade em conjunto, da mesma forma que a linguagem e a moral". (PONCE, 2003, p. 19)

Fica claro, portanto, que as sociedades primitivas, até este momento, caracterizam-se pela ausência de classes sociais. É por conta disso que a educação deriva, em verdade, de uma estrutura hegemônica em relação ao ambiente social e interesses comuns que se realizam de maneira espontânea ou integral pelos membros da coletividade. (PONCE, 2003)

No entanto, o processo histórico se modifica, traz novas nuances de acordo com o desenvolvimento próprio das sociedades. O ambiente para o surgimento das classes sociais surge. Uma mudança radical se inicia. Em primeiro lugar, é importante entender que as classes sociais não surgiram concomitantemente com as classes consideradas dominantes; apareceram como classes que, no decorrer de algumas centenas de anos, se fariam dominantes e passariam a lutar por sua hegemonia e domínio. (PONCE, 2003)

De acordo com Ponce (2003, p. 22), as classes sociais surgem a partir de dois fatores específicos: a) "o escasso rendimento do trabalho humano"; e b) "a substituição da propriedade comum pela propriedade privada". Estes dois elementos são centrais para a compreensão desse processo, pois foi a partir de então que as coletividades começaram a produzir além daquilo que era necessário para a sua subsistência. A partir do momento que surge a possibilidade de acúmulo - tendo em vista uma maior produção 
- novas relações surgem, possibilitando pequenas trocas e negociações entre grupos e comunidades diversas.

Um novo contexto, portanto, em que classes sociais cada vez mais economicamente distantes começam a surgir. Nesse sentido, vale ressaltar que

[...] com o desaparecimento dos interesses comuns a todos os membros iguais de um grupo e a sua substituição por interesses distintos, pouco a pouco antagônicos, o processo educativo, que até então era único, sofreu uma partição: a desigualdade econômica entre os 'organizadores' - cada vez mais exploradores - e os 'executores' - cada vez mais explorados - trouxe, necessariamente, a desigualdade das educações respectivas. (PONCE, 2003, p. 26, grifos do autor)

Aqui surge um elemento de destaque: a desigualdade das educações respectivas. Organizadores e executores se envolveriam em um longo processo que, nos moldes atuais, resultaram no pragmatismo da maneira como o entendemos: um pragmatismo educacional voltado para favorecer e manter um sistema desigual; um pragmatismo que transforma indivíduos em mão de obra barata e alienada, cansada. Um pragmatismo que se inclina para uma formação técnica que ignora o indivíduo em toda a sua complexidade. O ser humano passa a ser mero instrumento, mera engrenagem para o funcionamento de um sistema criado para manter as classes executoras invisibilizadas, silenciadas, docilizadas.

Ao abordar esse problema, Mészáros (2008, p. 15-16, grifos do autor) explica o seguinte:

A educação, que poderia ser uma alavanca essencial para a mudança, tornou-se instrumento daqueles estigmas da sociedade capitalista: 'fornecer os conhecimentos e o pessoal necessário à maquinaria produtiva em expansão do sistema capitalista, mas também gerar e transmitir um quadro de valores que legitima os interesses dominantes'. Se no pré-capitalismo a desigualdade era explícita e assumida como tal, no capitalismo - a sociedade mais desigual de toda a história -, para que se aceite que 'todos são iguais diante da lei', se faz necessário um sistema ideológico que proclame e inculque cotidianamente esses valores na mente das pessoas.

O surgimento de uma sociedade dividida em classes configurou o que no futuro seria identificado como um dos sistemas mais 
desiguais que já vigorou na história da humanidade. No decorrer do processo educacional ver-se-á uma educação com base ideológica pautada nas crenças e ideias das classes dominantes; não será dado às classes menos favorecidas oportunidade de participarem dos espaços educacionais, estes que passam a institucionalizar-se de maneira a causar cada vez mais separação entre as classes que organizam e as que executam.

Além dos elementos supracitados, o surgimento de uma sociedade em classes e da propriedade privada ocasionaram outros dois fatores importantes, que ditariam grande parte dos processos educacionais que se seguiram, em especial durante a Idade Média. Além do excedente de mercadoria, esses elementos trouxeram para o âmbito social uma religião com deuses, a autoridade do pai e a submissão da mulher e dos filhos à essa autoridade e, ainda, a separação entre trabalhadores e sábios. As consequências desse processo são vistas, claramente, das sociedades burguesas do século XVIII à contemporaneidade.

Finalmente, surge uma importante instituição que, segundo Ponce (2003) tratará de garantir, de maneira ainda mais acentuada, os privilégios das classes hegemônicas. O Estado, logo a partir de sua constituição, teria um único objetivo, um propósito central: garantir a permanência da classe burguesa nas posições de domínio. Era necessário, de fato, uma instituição como esta.

Neste período, um novo panorama se forma: "assegurar a superioridade militar sobre as classes submetidas, eis o fim supremo da educação". (PONCE, 2003, p. 41) Além do domínio imposto às pessoas que contraiam algum tipo de dívida, a guerra e o movimento militar tornaram-se importante fator dentro de um sistema que se faria capitalista anos mais tarde. Este contexto agravou, sobremaneira, a diferença entre as classes.

[...] à medida que esses trabalhadores'dóceis e ativos' [...] aumentavam em número, o proprietário não só se distanciava das suas terras, como começava a considerar como próprio de escravos ou de pobretões o trabalho direto da terra, ou qualquer outra forma de trabalho. 'Os trabalhadores são quase todos escravos', afirma Aristóteles. 'Nunca uma república bem organizada os admitirá entre os seus cidadãos e, se os admitir, não lhes concederá a totalidade dos direitos cívicos, direitos esses que devem ser reservados aos que não necessitam trabalhar para viver'. Aristóteles proibia terminantemente 
que se ensinasse aos jovens as artes mecânicas e os trabalhos assalariados: 'porque não somente alteram a beleza do corpo, como também tiram ao pensamento toda atividade e elevação' (PONCE, 2003, p. 45, grifos do autor)

O trecho acima apresenta uma gênese de muito do que hoje se constitui a ideologia da classe dominante. Ideologia essa tão alimentada e acriticamente assimilada pelas Instituições sociais que a própria classe subalterna reproduz sobre seus semelhantes, sempre que possível. (FREIRE, 2014). É nesse contexto que a classe hegemônica direcionará seus filhos para uma formação completamente distanciada das da classe executora. Estes, os futuros dominantes, deverão ser educados tendo em vista esse propósito: sua criação foi direcionada para que tenham condições de gerenciar as classes subalternas. "Trabalhar para viver" passa a ser, então, algo desprezível, reservados aos que não nasceram para a grandeza. (PONCE, 2003)

O processo descrito supra se acentuará de tal maneira que a própria educação ganhará um caráter mercadológico. Conforme assevera Mészáros (2008, p. 16) "[...] no reino do capital, a educação é, ela mesma, uma mercadoria. Daí a crise do sistema público de ensino, pressionado pelas demandas do capital e pelo esmagamento dos cortes de recursos dos orçamentos públicos". Afirma ainda que "[...] uma sociedade que impede a emancipação só pode transformar os espaços educacionais em shopping centers, funcionais à sua lógica do consumo e do lucro. (MÉSZÁROS, 2008, p. 16)

Em resumo, da antiguidade ao estabelecimento de uma educação para a classe burguesa - sabemos que o salto foi longo, no entanto, necessário - o que se tem é o impedimento da emancipação das classes subalternas. Como veremos na seção seguinte, isto se constituirá um forte empecilho à uma educação conforme os termos de Arendt: uma educação que leva indivíduos à ação, ao espaço público do diálogo, onde predomina a pluralidade, propício ao surgimento do novo, do inesperado, portanto avesso a qualquer forma de pragmatismo da maneira como presente na contemporaneidade. (ARENDT, 2013)

Entrementes, será o feudalismo que reforçará algumas das estruturas que, a longo prazo, culminarão em um ethos voltado para os conceitos de Deus, família e pátria. De acordo com Ponce (2003, p. 85), "[...] enquanto o escravo e o servo sofriam sob os seus senhores, o cristianismo proclamava que eles eram iguais diante de 
Deus. Descoberta maravilhosa que respeitava o status quo terreno, enquanto não chegava o momento de alterá-lo, mas no céu...". É nesse contexto que os monastérios, junto às classes hegemônicas, estabelecerão o seu domínio educacional, político e ideológico.

É nesse cenário que surgem as escolas - os monastérios que podiam ser frequentados pela massa. No entanto, isso não deve ser confundido com um possível avanço em relação a uma educação efetiva das classes trabalhadoras. Entre seus propósitos, as escolas monásticas buscavam mesmo era docilizar as massas, transformando-as em entes que respeitam e se submetem às classes dominantes; contribuíram, em verdade, para a manutenção do status quo, além, é claro, de ensinar a doutrina cristã. (PONCE, 2003)

Será neste contexto que mais propriamente surgirá, no sentido histórico, a classe burguesa. Ponce (2003, p. 95) lembra que

[...] as cidades se transformaram em centros de comércio, onde os produtores trocavam os seus produtos. Surgiu, então, uma profunda transformação: o que até ontem era apenas uma fortaleza, começava agora a ser um mercado. Os seus habitantes, chamados burgueses, acabaram se fundindo em uma classe predisposta a uma vida pacífica e urbana, bem distinta da vida guerreira e rural, que era apanágio da nobreza.

Esse novo movimento forçará a Igreja a tomar uma nova postura frente as suas diretrizes educacionais. "O aparecimento dos burgueses citadinos obrigou a Igreja a deslocar o centro do seu ensino. Se, até o século XI, poderiam bastar as escolas dos monastérios, agora já eram necessárias as escolas das catedrais". (PONCE, 2003, p. 96). Até este momento, vale ressaltar, a burguesia não possuía intenções revolucionárias; isso mudará sobremaneira no quadro que se formará a partir da Revolução Francesa de 1789.

Não muito tempo depois, o "[...] homem feudal sucumbira. Os burgueses compraram as suas terras; a pólvora derrubou os seus castelos. Os navios apontavam agora as rotas de um continente remoto [...], que só poderia ser conquistado mediante a indústria e o comércio". (PONCE, 2003, p. 109)

Daqui em diante o pragmatismo ocupará um novo espaço. É neste estado de coisas que, de fato, "o útil e o prático passam [...] a constituir preocupações de primeiro plano. Em oposição à vida 'santa' dos monges e à vida 'cavalheiresca' dos barões, os humanistas defendiam outra espécie de vida, que fosse mais laica do 
que aquela, e menos predadora do que esta". (PONCE, 2003, p. 113, grifos do autor)

A partir de então, se dará prosseguimento a um longo processo de alienação das massas. Entre outras características, o que surgirá, no que diz respeito aos processos educacionais, é um incentivo ao acúmulo de conhecimentos e não propriamente a compreensão efetiva do mundo (MÉSZÁROS, 2008). A necessidade que o sistema tem de que as massas trabalhadoras acumulem conhecimentos significa, unicamente, conhecimentos úteis ao seu trabalho enquanto mão de obra, enquanto produtora da riqueza da classe dominante.

De acordo com Mészáros (2008, p. 35) o que ocorre de fato é que, nos últimos 150 anos, a educação que se passa no meio institucionalizado teve como função basicamente fornecer "[...] os conhecimentos e o pessoal necessário à máquina produtiva em expansão do sistema do capital, como também gerar e transmitir um quadro de valores que legitima os interesses dominantes".

São as determinações do capital, portanto, que ditam os processos educacionais de formação. As escolas, longe de serem as únicas que contribuem para este quadro de coisas, estão, no entanto, entre as principais instituições que corroboram com esse sistema global de internalização. (MÉSZÁROS, 2008) É necessário, portanto, uma perspectiva que rompa com esses processos e não apenas os reformem. Assim,

[...] o sentido da mudança educacional radical não pode ser senão o rasgar da camisa de força da lógica incorrigível do sistema: perseguir de modo planejado e consistente uma estratégia de rompimento do controle exercido pelo capital, com todos os meios disponíveis, bem como com todos os meios ainda a ser inventados, e que tenham o mesmo espírito. (MÉSZÁROS, 2008, p. 35)

É nesse sentido que partiremos para apresentar alguns conceitos e categoriais arendtianas, tais como a singularidade, a pluralidade, a natalidade e a liberdade resultante desse processo, a fim de apontar uma educação onde a valorização da dignidade humana seja levada ao extremo de nossa atenção, ensejando a reconstrução do pragmatismo desenvolvido no sistema educacional ao longo da história. 


\section{Educação em crise: o pensamento arendtiano e a crítica ao pragmatismo}

A humanidade passou, no decorrer de sua história, por diversas transformações em suas estruturas políticas, econômicas e sociais. De fato, a cada ciclo, que varia tanto no tempo quanto no espaço, definições sobre a vida, sobre o modo de viver e de se educar se transformaram profundamente. Entre as mais influentes perspectivas estão a da pensadora alemã Hannah Arendt (2013) que vê a essência da "educação na natalidade": a realidade de que seres humanos nascem para o mundo, com a potencialidade de renová-lo. ${ }^{1}$

A natalidade, portanto, é condição sine qua non para a educação. A ausência desse processo representa a própria ausência e incapacidade de renovação no mundo. (ARENDT, 2013). Nesse contexto, e de fato, a crise educacional apontada por Arendt (2013, p. 222) é um problema político e não algo mais simples. Para a autora, o problema vai muito além de apenas entender "por que Joãozinho não sabe ler". O risco está de fato em tratar o problema educacional como um problema de fronteiras históricas e nacionais bem delimitadas, de maneira que se atente apenas para os envolvidos que são imediatamente afetados. Isso é uma falácia.

Para Arendt (2013, p. 222) "pode-se admitir como uma regra neste século que qualquer coisa que seja possível em um país pode, em futuro previsível, ser igualmente possível em praticamente qualquer outro país".

A não atenção aos equívocos citados supra ocasionam algo ainda pior. É de suma importância que se preocupe com uma determinada situação problemática mesmo que em um momento específico não se esteja diretamente envolvido com ela ou não se sinta afetado por ela. A crise oportuniza que o pensamento se volte para aquilo que é essencial na educação: "a essência da educação é a natalidade, o fato de que seres nascem para o mundo". (ARENDT, 2013, p. 223)

Adotada aqui como processo que resultou da crise moderna que teve como epicentro os regimes totalitários, a educação surge como importante categoria de análise, capaz inclusive de trazer à tona profundas reflexões sobre a maneira de estar e de existir no mundo marcado pela banalização da maldade e da violência, com declínio da autoridade e da tradição.

Nesse sentido, entre as principais características que sinalizam a crise, explica a autora, está o desaparecimento do senso comum. ${ }^{2}$
(1) Sobre isso, é importante destacar a contribuição de Mészáros (2008, p. 13), ao firmar que: "educar não é mera transferência de conhecimentos, mas sim conscientização e testemunho de vida. É construir, libertar o ser humano das cadeias do determinismo neoliberal, reconhecendo que a história é um campo aberto de possibilidades".

(2) "[...] o senso comum pressupõe um mundo comum no qual todos cabemos e onde podemos viver juntos, por possuirmos um sentido que controla e ajusta todos os dados sensoriais estritamente particulares àqueles de todos os outros". (ARENDT, 2002, p. 48) 
(3) A autora se utiliza da expressão "Homem" com inicial maiúscula para se referir a humanidade.
De acordo com Arendt (2013), em "[...] toda crise, é destruída uma parte do mundo, alguma coisa comum a todos nós. A falência do bom senso aponta, como uma vara mágica, o lugar em que ocorreu este desmoronamento". (ARENDT, 2013, p. 227)

Este aspecto do pensamento arendtiano está vinculado ao que a autora chama de tradição. Explicamos: após o materialismo histórico dialético de Karl Marx e o existencialismo, especialmente nas vertentes de Søren Kierkegaard e Friedrich Nietsche, o Homem ${ }^{3}$ deixa de ter uma base sólida sob a qual se situar e passa a andar entre dúvidas e incertezas. Estes marcos históricos são significativos no processo que a pensadora alemã entendeu como a quebra da tradição.

Nesse ambiente de crise da educação é que se estabelece a noção de meritocracia. Modelo intentado primeiramente na Inglaterra, a meritocracia não se diferencia do estabelecimento de uma oligarquia. No entanto, no lugar de ser de riqueza ou nascimento é de talento. Nesse sentido, Arendt (2013, p. 229) compreende que a "meritocracia contradiz, tanto quanto qualquer outra oligarquia, o princípio da igualdade que rege uma democracia igualitária".

Hannah Arendt tira suas primeiras conclusões e reflexões a partir do ineditismo trazido pelos regimes totalitários. De fato, para a autora, os campos de concentração foram laboratórios de homens sem mundo. No projeto totalitário de desumanização dos modernos movimentos ideológicos de massas, Hannah Arendt não via nada além de um mundo demente que funcionava. (ARENDT, 2012) Estas questões incidem, de acordo com a pensadora, nos processos educacionais atuais, pós Segunda Guerra Mundial.

Contemporâneo de Hannah Arendt, Theodor Adorno, em texto de título Educação após Auschwitz, corrobora o pensamento da filósofa Hannah Arendt, elucidando a necessidade de que os acontecimentos do maior campo de concentração e extermínio nazista não se repita: segundo Adorno, essa seria a primeira de todas as tarefas da educação. Conforme explica, "a pouca consciência em relação a essa exigência e as questões que ela levanta provam que a monstruosidade não calou fundo nas pessoas, sintoma da persistência da possibilidade de que se repita no que depender do estado de consciência e de inconsciência das pessoas". (ADORNO, 1995, p. 119)

Nesse contexto, Adorno (1995, p. 119) também elucida um ponto fundamental: "a barbárie continuará existindo enquanto persistem 
no que tem de fundamental as condições que geram esta regressão". De fato, Hannah Arendt apontaria também como a existência dos campos de concentração e extermínio se constituíam como o início e não o fim do processo de desumanização. (ARENDT, 2013) Essa persistência das condições que geram a regressão, apontada por Adorno (1995), se estabelece como um entre os pontos de partida possíveis para a adoção de elementos teóricos e metodológicos que possibilitem a superação de tais condições. Parte desse subsídio encontramos em Arendt, especialmente em sua elaboração sobre a educação.

No âmbito de uma desumanização integral do mundo, Arendt (2013) apresenta o homem como um "ser do mundo". Nesse sentido, fala sobre a criação de um âmbito inter-humano propício ao aparecimento de homens plurais, tanto no sentido da ação quanto no sentido do discurso, características fundamentais de homens que agem no espaço público e, portanto, exercem sua liberdade, indo muito além de objetivos pragmáticos ou pautados em elementos meritocráticos.

É necessário, por conta disso, por fim a interrupção da iniciativa espontânea do agir e do falar se se tem por objetivo a superação do pragmatismo. É nesse espaço que a educação surge como importante instrumento.

De acordo com Arendt (2013, p. 234) a "educação está entre as atividades mais elementares e necessárias da sociedade humana, que jamais permanece tal qual é, porém se renova continuamente através [...] da vinda de novos seres humanos". Conforme a autora, a criança é introduzida no mundo através da escola, no entanto, não se deve confundir este espaço com o mundo comum propriamente dito. De fato, o ambiente escolar é "a instituição que interpomos entre o domínio privado do lar e o mundo com o fito de fazer com que seja possível a transição, de alguma forma, da família para o mundo". (ARENDT, 2013, p. 238)

Hannah Arendt (2013) considerava tão importante o propósito do espaço escolar que chegou mesmo a afirmar que qualquer pessoa que se recusasse a assumir a responsabilidade coletiva pelo mundo não deveria ter crianças. Este aspecto do pensamento arendtiano demonstra o tamanho do comprometimento da autora com a ideia da preservação de um mundo comum de homens que possam existir no plural, onde sejam igualmente superadas estruturas com objetivos unicamente e exclusivamente pragmáticos. 
Vale ressaltar, que no âmbito de uma crise educacional, conforme proposto no início deste texto, "toda e qualquer responsabilidade pelo mundo está sendo rejeitada, seja a responsabilidade de dar ordens, seja a de obedecê-las". (ARENDT, 2013, p. 240) Para a pensadora, o que ocorre é que os adultos têm renegado a autoridade e isso significa dizer que, para o bem da verdade, "adultos se recusam a assumir a responsabilidade pelo mundo ao qual trouxeram as crianças". (ARENDT, 2013, p. 240)

Esse cuidado com a inserção correta da criança no mundo comum reside no fato de que, para Arendt, o potencial para pôr em ordem um mundo fora dos eixos reside nos novos. Sobre isso, em determinado momento a autora explica que sua "esperança está pendente sempre do novo que cada geração aporta; [...] tudo destruímos se tentarmos controlar os novos de tal modo que nós, os velhos, possamos ditar sua aparência futura". (ARENDT, 2013, p. 243)

Finalmente, para Arendt (2013, p. 246) "a função da escola é ensinar às crianças como o mundo é, e não instruí-las na arte de viver. Dado que o mundo é velho, sempre mais que elas mesmas, a aprendizagem volta-se inevitavelmente para o passado". Ao indicar às crianças as experiências históricas ocorridas no mundo é natural um desenvolvimento a posteriori que leve em conta tais eventos. Isso significa dizer que, por exemplo, ao ser instruída sobre os impactos negativos decorrentes dos regimes totalitários se evite, através das gerações que aprenderam, a existência de novos regimes totalitários.

No ambiente de uma crise da educação Arendt (2013, p. 247) apresenta duas conclusões parciais. A primeira diz respeito ao fato de que a "educação é o ponto em que decidimos se amamos o mundo o bastante para assumirmos a responsabilidade por ele e, com tal gesto, salvá-lo da ruína que seria inevitável não fosse a renovação e a vinda dos novos e dos jovens". A segunda faz referência ao fato de que a "educação é, também, onde decidimos se amamos nossas crianças o bastante para não as expulsar de nosso mundo e abandoná-las a seus próprios recursos, e tampouco arrancar de suas mãos a oportunidade de empreender alguma coisa nova". (ARENDT, 2013, p. 247)

É nesse aspecto que Hannah Arendt criticará o pragmatismo norte-americano, em artigo publicado em 1958 - The Crisis in Education - na revista Partisan Review. Arendt baseou suas refle- 
xões em três aspectos fundamentais: a) a emancipação do mundo infantil da autoridade dos adultos; b) a emancipação do ensino da pedagogia - que na época foram fortemente influenciados pela psicologia bem como por princípios do próprio pragmatismo; e, c) emancipação dos educadores no que diz respeito à responsabilidade do ensino, uma vez que centravam o aprendizado da criança nas suas experiências pessoais. (ARENDT, 2013)

Sobre os dois últimos aspectos cabem alguns apontamentos pormenorizados. Sobre o papel da Pedagogia, Arendt centrava sua crítica no fato de que ela "transformou-se em uma ciência do ensino em geral a ponto de se emancipar inteiramente da matéria efetiva a ser ensinada. Um professor, pensava-se, é um homem que pode simplesmente ensinar qualquer coisa". (ARENDT, 2013, p. 231)

Para Arendt, o contexto supracitado gerou um negligenciamento no processo de formação de professores no que dizia respeito às suas próprias matérias - especialmente a formação de professores de colégios públicos. Como consequência, o que se tem é que o "professor não-autoritário, que gostaria de se abster de todos os métodos de compulsão por ser capaz de confiar apenas em sua própria autoridade, não pode mais existir". (ARENDT, 2013, p. 231) O que se dá, a partir de então, é um ensino vazio; ensino que se centra em alvos de curto prazo, materiais; uma educação para o mundo do trabalho e não para a emancipação e criticidade.

Hannah Arendt acreditava que tais problemas precisavam ser superados, uma vez que, segundo ela, era necessário apresentar o mundo comum aos alunos de maneira que estes entendessem que este mesmo mundo existia antes deles e tinha necessidade, bem como potencialidade, para existir depois deles. É necessário, portanto, que as crianças - e os demais habitantes do mundo - se sintam em casa nesse mundo comum e plural.

\section{Considerações finais}

Buscar alternativas educacionais em meio a um processo que no decorrer de centenas de anos se fez excludente não se encerra numa única proposta, tampouco num único momento da história. Nosso objetivo, portanto, não foi de apontar o pensamento arendtiano como um remédio infalível para a solução do pragmatismo, mas sim, reconhecer na filosofia de Hannah Arendt aspectos voltados à educação que tem como foco o indivíduo em sua potencialida- 
de de transformação, de maneira a dar subsídios teóricos para a superação do modelo pragmático de educação que mais cegou do que formou cidadãos.

Aníbal Ponce e István Mészáros nos ofereceram subsídios suficientes para perceber que a própria estrutura educacional contemporânea, em sua essência, nasce da divisão, da exploração, da diferença de classes e, portanto, é excludente. Ao mostrar que vivemos no sistema econômico, político e social desigual, esses autores apontam, também, suas alternativas, que giram em torno de uma mudança essencial da própria sistemática capitalista.

Por sua vez, Hannah Arendt também deu suas razões para entender o sistema educacional moderno como um sistema em crise. E ela apresenta um caminho: cada pessoa representa a possibilidade do surgimento de algo inesperado, de algo que pode direcionar, de maneira completamente nova, a humanidade para uma vida plural, digna, singular.

O indivíduo, ao compreender seu papel no mundo comum dos homens, contribui, sobremaneira, para uma efetiva mudança desse mesmo mundo. Ao fugir de alternativas metafísicas, idealistas a ponto de serem mesmo utópicas, Arendt, a partir da experiência grega, aponta categorias e possibilidades reais de mudança do status quo, entre as quais temos a necessidade de compreender e inserir em nossos sistemas educacionais o caráter singular e plural dos indivíduos.

A superação do pragmatismo na educação, cremos, desenvolve-se a partir desse reconhecimento. Assumir que os educandos-entre os quais as crianças são tidas como os principais- devem possuir um caráter autônomo e renovador é um dos caminhos possíveis na tarefa de evitar que sejam tratados como meros sujeitos depositantes de informações imediatistas, que reforçam a meritocracia e o pragmatismo.

As alternativas para construir uma educação cuja principal referência seja o ser humano encontra-se, portanto, na natalidade - o novo no mundo, cada pessoa representa a possibilidade do surgimento de algo inesperado, de algo que pode direcionar, de maneira completamente nova, a humanidade para uma vida plural, digna, singular. O processo de superação do pragmatismo deve, necessariamente, passar por esse reconhecimento, especialmente por seu elemento inovador e renovador. 


\title{
Educationand Pragmatism: dialogues between Aníbal Ponce, István Mészáros and Hannah Arendt
}

\begin{abstract}
Educate for freedom and emancipation or to train professionals who are fit for the job market? How did education give way to pragmatism and how to reflect on alternatives regarding this formative model? Thinking about education is a complex and multidimensional task, since its history was not born, nor was it expanded from a uniform, homogeneous movement. Depending on the location, the educational processes can be completely different, whose role of education varied depending on the agents or recipients of this system. Some of these processes were "successful" when considering the minority to be achieved. When education subsequently reaches the working classes, its focus is on preparing labor for the labor market; exclusively a technical pragmatism is sought. In this sense, this article aims to reflect on educational processes and perspectives, through a dialogue between the well-known authors Aníbal Ponce and István Mészáros and the philosopher Hannah Arendt. We will use the authors to point how the history of education has, over the centuries, inclined to pragmatism; From Hannah Arendt, we will extract an educational perspective which, we believe, emerges as an alternative to be implemented in the practices in educational processes, whose main reference is the human being, still in formation. However, it is not a matter of offering a ready-made proposal that seeks to solve the problem of pragmatism in a complete or simplistic manner. It is really a matter of reflecting on possible paths that can be traced from Arendtian thinking.
\end{abstract}

Keywords: Education. Pragmatism. Citizen Formation.

\section{Educación y pragmatismo: diálogos entre Aníbal Ponce, István Mészáros y Hannah Arendt}

Resumen: Educar para la libertad y la emancipación o para formar profesionales capaces de trabajar? Cómo dio paso la educación al pragmatismo y cómo reflexionar sobre las alternativas a este modelo formativo? Pensar en la educación es una tarea compleja y multidimensional, ya que su historia no nació ni se expandió por un movimiento uniforme y homogéneo. Según el lugar del mundo, los procesos educativos se hicieron completamente diferentes, cujo el papel de la educación en modelos y alternativas variadas dependiendo de los autores o receptores de este sistema. Algunos de estos procesos fueron "exitosos" si consideramos la minoría a ser alcanzada; En este sentido, este artículo tiene como objetivo reflexionar sobre procesos y perspectivas educativas, a través de un diálogo entre los educadores Aníbal Ponce e István Mészáros y la filósofa Hannah Arendt. Utilizaremos a los autores para punto cómo la historia de la educación, a lo largo de los siglos, se ha inclinado hacia el pragmatismo; Dela autora, extraeremos una perspectiva educativa que, creemos, emerge como una alternativa en procesos educativos, cuya referencia principal es el ser humano, aún en formación. Sin embargo, no se trata de ofrecer una propuesta preparada que busque resolver el problema del pragmatismo de manera completa o simplista. En realidad se trata de una cuestión de reflexionar sobre los posibles caminos que se pueden seguir desde el pensamiento arendtiano.

Palabras clave: Educación. Pragmatismo. Formación ciudadana. 


\section{Referências}

ADORNO, Theodor W. Educação após Auschwitz. Educação e emancipação, São Paulo, v. 3, p. 119-138, 1995.

ALMEIDA, Vanessa Sievers de. Educação e liberdade em Hannah Arendt. Educação e Pesquisa, São Paulo, v. 34, n. 3, p. 465-479, 2008.

ARENDT, Hannah. Origens do totalitarismo: antissemitismo, imperialismo e totalitarismo: Tradução Roberto Raposo. São Paulo: Companhia das Letras, 2012.

ARENDT, Hannah. A condição humana. 12. ed. Rio de Janeiro: Forense Universitária, 2014.

ARENDT. Hannah. A dignidade da política. Rio de Janeiro: RelumeDumará, 2002.

ARENDT. Hannah. Entre o passado e o futuro. 7. ed. São Paulo: Perspectiva, 2013.

FREIRE, Paulo. Pedagogia do oprimido. 57. ed. rev. atual. Rio de Janeiro: Paz e Terra, 2014.

MÉSZÁROS, István. A educação para além do capital. 2. ed. São Paulo: Boitempo, 2008.

PONCE, Aníbal. Educação e luta de classes. 20. ed. São Paulo: Cortez, 2003.

Submetido em: 05/11/2019

Aceito em: 01/04/2020 